\title{
Consultation Liaison Psychiatry: A Study at GMC
}

\author{
Thapa DK ${ }^{1}$, Lamichhane $\mathbf{N}^{2}$, Timasina $\mathbf{R}^{3}$, Subedi $\mathrm{S}^{4}$ \\ 1. Associate Professor, Department of Psychiatry, GMC, Pokhara, Nepal 2. Associate Professor, \\ Department of Psychiatry, GMC, Pokhara, Nepal 3. Lecturer, Department of Psychiatry, GMC, Pokhara, \\ Nepal 4. Associate Professor, Department of Psychiatry, UCMS, Bhairahawa, Nepal
}

E-mail *Corresponding author: ddthapa@hotmail.com

\begin{abstract}
Introduction: Consultation Liaison Psychiatry is the fusion of Psychiatry and general medicine. The presence of mental disorders in physically ill people is often associated with poor medication compliance, slower or incomplete recovery, poor participation in the rehabilitation program, increased mortality and the high psychiatric comorbidity to other medical disorders in hospitalized patients significantly increases their length of hospital stay. Therefore, mental health professionals have important role to provide holistic care to people with various physical illnesses.
\end{abstract}

Material And Method: This is a hospital- based, cross- sectional, descriptive study conducted for the period of six months, from 1st Baisakh, 2076 (14th April, 2019) to 30th Asoj, 2076 (17th October, 2019) at the department of Psychiatry at Gandaki Medical College, Pokhara, Nepal. This study was conducted to diagnose the various psychiatric disorders among the in-patients suffering from other physical illness, which were referred from other medical specialties. The psychiatric evaluation and the diagnosis were made by the consultant psychiatrists.

Results: The total number of cases enrolled were163, out of which male were 96 (58.8\%) and female were 67 $(41.2 \%)$ in numbers. The age of the patients ranged from 6 years to 90 years with the mean age of $41.17 \pm 18.57$ years. Majority of the in- patient cases referred for psychiatric assessment were from the Internal medicine (42.3\%), followed by ICU (23.3\%), Surgery (12.8\%), Orthopedics (9.8\%) and Gynecology and Obstetrics (7.3\%) specialty. Among the in- patient referral cases, the most common psychiatric diagnosis was substance dependence syndrome $(39.2 \%)$, followed by anxiety disorder $(17.1 \%)$, delirium due to general medical condition $(12.2 \%)$, depression $(6.7 \%)$, seizure disorder (6.7\%) and intentional self harm (5.5\%).

Conclusion: Under Consultation Liaison Psychiatry, the most common diagnoses to look for are the substance dependence syndrome, anxiety disorder, delirium, depression, seizure disorder, self harm etc.

Keywords: Consultation Liaison Psychiatry, Substance Use, Nepal

\section{INTRODUCTION}

Consultation Liaison Psychiatry (CLP), the fusion of Psychiatry and general medicine, 1 dates back to $19222^{2}$ and even earlier ${ }^{3}$. Physical illnesses of any kind are often associated with significant emotional and social consequences. The psychosocial consequences often are severe enough to manifest as various psychiatric syndromes. 4

Approximately $30 \%$ of all patients in general medical settings exhibit psychiatric disorders, with delirium being detected in $10 \%$ of all medical inpatients and 30\% in certain high-risk patient groups. An alarming two-thirds of high- frequency users of medical services have a psychiatric disorder, most commonly depression $(23 \%)$, anxiety $(22 \%)$, and somatic symptom disorder $(20 \%) .{ }^{5}$

The presence of mental disorders in physically ill people is often associated with poor medication compliance, slower or incomplete recovery, poor participation in the rehabilitation program, increased mortality ${ }^{4}$ and the high psychiatric comorbidity to other medical disorders in hospitalized patients significantly increases their length of hospital stay. 2 However, mental disorders in physically ill are underrecognized 6 and undertreated. 2 
Therefore, mental health professionals have important role to provide holistic care to people with various physical illnesses.

Despite its importance, it was only in 2003, that the American Board of Medical Specialties recognized CLP and approved the issuance of subspecialty certification in "Psychosomatic Medicine" by the American Board of Psychiatry and Neurology. The goal of such subspecialty status was to promote the psychiatric care of patients with complex medical, surgical, obstetrical, and neurological conditions and improve training and research in CLP. ${ }^{7}$

In the context of Nepal, the psychiatry service is mainly available at psychiatry centre which is now the part of general hospital settings and all the medical colleges across the country. This study was conducted to diagnose the various psychiatric conditions in the in-patients suffering from other physical illness admitted in Gandaki Medical College.

\section{MATERIAL AND METHOD}

This study was conducted for the period of six months, from $1^{\text {st }}$ Baisakh, 2076 (14 $4^{\text {th }}$ April, 2019) to 30th Asoj, 2076 (17th October, 2019) at the department of Psychiatry at Gandaki Medical College, Pokhara, Nepal after taking the ethical clearance. This is a hospital- based, crosssectional, descriptive study. This study was conducted to diagnose the various psychiatric disorders among the in-patients suffering from other physical illness, which were referred from other medical specialties.

\section{Inclusion criteria:}

All the consenting in- patients of any age and gender, from any medical specialties, regardless of their physical illness, who were referred for psychiatric evaluation were included in the study.

\section{Exclusion criteria:}

Any out- patient referral, referral from Emergency and patients who didn't consent were not enrolled in the study.

The psychiatric evaluation and the diagnosis were made by the consultant psychiatrists from the department based on ICD-10 DCR criteria and the needful data were collected by using the semi- structured performa and discussed.

\section{RESULT}

This is a hospital- based, cross- sectional, descriptive study of 6 months duration, from $1^{\text {st }}$ Baisakh, 2076 (14 ${ }^{\text {th }}$ April, 2019) to $30^{\text {th }}$ Asoj, 2076 (17th October, 2019) done at the department of Psychiatry at Gandaki Medical College, Pokhara, Nepal . The total number of cases enrolled were163, out of which male were 96 $(58.8 \%)$ and female were $67(41.2 \%)$ in numbers.

The age of the patients ranged from 6 years to 90 years with the mean age of 41.17 years with standard deviation of \pm 18.57 and the median age was 40 years. The majority of the referrals belonged to the age group of 21- 40 years (41.1\%). (Table 1)

Table 1: Age Distribution Of the Referred Subjects

\begin{tabular}{|l|l|r|}
\hline SN & Age group & Frequency $(\%)$ \\
\hline 1 & Less than 20 years & $21(12.8 \%)$ \\
\hline 2 & $21-40$ years & $67(41.1 \%)$ \\
\hline 3 & $41-60$ years & $49(30 \%)$ \\
\hline 4 & $61-80$ years & $22(13.5 \%)$ \\
\hline 5 & More than 80 years & $4(2.4 \%)$ \\
\hline Total & & $163(100 \%)$ \\
\hline
\end{tabular}

Table 2: Sources Of Referral

\begin{tabular}{|l|l|r|}
\hline SN & Specialty & Frequency (\%) \\
\hline 1 & Internal Medicine & $69(42.3 \%)$ \\
\hline 2 & $\begin{array}{l}\text { Intensive care unit } \\
\text { (ICU) }\end{array}$ & $38(23.3 \%)$ \\
\hline & $\begin{array}{l}\text { Medical ICU } \\
\text { Surgical ICU }\end{array}$ & 2 \\
\hline 3 & Surgery & $21(12.8 \%)$ \\
\hline 4 & Orthopedics & $16(9.8 \%)$ \\
\hline 5 & $\begin{array}{l}\text { Gynecology and } \\
\text { Obstetrics }\end{array}$ & $12(7.3 \%)$ \\
\hline 6 & Ear Nose and Throat & $2(2.4 \%)$ \\
\hline 7 & Pediatrics & $1(0.6 \%)$ \\
\hline 8 & Eye & $163(100 \%)$ \\
\hline Total & \multicolumn{2}{|l}{} \\
\hline
\end{tabular}

Majority of the in- patient cases referred for psychiatric assessment were from the Internal medicine $(42.3 \%)$, followed by ICU $(23.3 \%)$, Surgery (12.8\%), Orthopedics (9.8\%) and Gynecology and Obstetrics (7.3\%) specialty. There were few referrals from other specialty. 
Table 3: Diagnosis of the referred Cases

\begin{tabular}{|l|l|l|}
\hline SN & Psychiatric Diagnosis & $\begin{array}{l}\text { Frequency } \\
\mathbf{( \% )}\end{array}$ \\
\hline 1 & $\begin{array}{l}\text { Substance Dependence } \\
\text { Syndrome }\end{array}$ & $64(39.2 \%)$ \\
\hline & $\begin{array}{l}\text { Alcohol Dependence } \\
\text { Syndrome } \\
\text { Opioids Dependence } \\
\text { Syndrome } \\
\text { Benzodiazepine Dependence } \\
\text { Syndrome }\end{array}$ & 38 \\
\hline 2 & Anxiety Disorder & $28(17.1 \%)$ \\
\hline 3 & $\begin{array}{l}\text { Delirium due to general } \\
\text { medical condition }\end{array}$ & $20(12.2 \%)$ \\
\hline 4 & Depression & $11(6.7 \%)$ \\
\hline 5 & Seizure Disorder & $11(6.7 \%)$ \\
\hline & $\begin{array}{l}\text { Idiopathic } \\
\text { Seizure with Mental } \\
\text { Retardation } \\
\text { Seizure with Organic } \\
\text { Psychosis }\end{array}$ & 7 \\
\hline 6 & $\begin{array}{l}\text { Intentional self harm: Non } \\
\text { suicidal }\end{array}$ & 2 \\
\hline 7 & Headache Disorder & $8(5.5 \%)$ \\
\hline 8 & Others & $12(7.3 \%)$ \\
\hline Total & $\begin{array}{l}\text { Deferred } \\
\text { Dissociative Disorder } \\
\text { Sleeping Disorder } \\
\text { Schizophrenia } \\
\text { Dementia }\end{array}$ & 4 \\
\hline & 3 \\
\hline
\end{tabular}

Among the in- patient referral cases, the most common psychiatric diagnosis was substance dependence syndrome (39.2\%), followed by anxiety disorder (17.1\%), delirium due to general medical condition (12.2\%), depression $(6.7 \%)$, seizure disorder $(6.7 \%)$ and intentional self harm (5.5\%). Suicidal attempt was seen in 3 cases only; out of which 2 cases were associated with depression and the other one with schizophrenia.

\section{DISCUSSION:}

Over the past two decades research in Psychiatry has identified CLP as "the guardian of holistic approach to the patient". ${ }^{8}$ The CLP is a subspecialty of Psychiatry that provides psychiatric treatment to patients attending general hospitals. Therefore, it deals with the interface between physical and psychological health. Lipowski defined CLP as a subspecialty of psychiatry that involves providing clinical service, teaching and carrying out research at the borderland of psychiatry and medicine. ${ }^{9}$

The CLP objectives and operating procedures have evolved in recent years from administration of psychiatric treatment 10 to integrating therapy 11 into the bio-psyo-social model along the lines of the recommendation from an editorial in the Lancet "No health without mental health" ${ }^{12}$. It is worth noting that psychiatric disorders, even when sub-clinical ${ }^{13}$, worsen outcome, lengthen hospital stays and are associated with increased mortality and use of health service resources. ${ }^{14,15}$ The early detection and treatment of psychological distress and psychiatric disorders in comorbidity are known to reduce health care costs significantly. ${ }^{16}$ In such view, it is good that the provision of mental health care services has moved from institutional based care to a more community and general hospital based care, 8,17,18 thus bringing greater opportunities of close collaboration and liaison between the psychiatrists and other specialists.

In our study, the total number of cases enrolled were 163 , out of which male were $96(58.8 \%)$ and female were $67(41.2 \%)$ in numbers. This finding was similar to the study by Grover et al in which males were the majority of the cases $(60.3 \%) .19$ In our study, the age of the patients ranged from 6 years to 90 years with the mean age of $41.17 \pm$ 18.57 years and the most common age group referred for the consultation was from 21- 40 years $(41.1 \%)$. In the study by Grover et al the dominant age group was from 16- 30 years of age $(40.7 \%) .{ }^{19}$

Many of the patients requiring psychiatric care may not come directly to psychiatric service and in such cases the needful referral can be diagnostic, therapeutic and holistic. In our study, we had referrals from various medical specialties; Internal medicine $(42.3 \%)$, ICU $(23.3 \%)$, Surgery $(12.8 \%)$, Orthopedics $(9.8 \%)$ and Gynecology and Obstetrics $(7.3 \%)$ specialty. There were few referrals from other specialty like ENT, Pediatrics and Eye.

Regarding the referral rate, there are only a few studies from developing countries and from Asia. ${ }^{19}$ An Indian study by Kelkar DK et al that 
evaluated 100 consecutive referrals from emergency, reported a referral rate of $5.4 \%$ to the psychiatry services with 2.8 referrals per day. ${ }^{20}$ Other Indian studies by Adityanjee et al and Bhatia MS et al have reported a psychiatry referral rate of $1.5-2 \%$ with 0.9 psychiatry referrals per day. ${ }^{21,} 22$ A study from Pakistan, by Khan AG et al, found that when all patients attending the emergency were screened for psychiatric morbidity, the psychiatric morbidity was found in $2.3 \%$ of patients. ${ }^{23}$ In study by Grover et al, the major sources of referral were emergency and surgical services. ${ }^{19}$ This is to stress that mental health must not be ignored because of the focus on physical illness only.

The prevalence of mental illness among hospital inpatients ranged from 26.1 to $38.7 \%$. 24, 25 Among the mental illnesses found among inpatients, prevalence of depression varied from 5.1 to $33.5 \%$ and anxiety disorders were estimated around $5.8 \%$. ${ }^{24}$ According to study by Bronheim et al, 5 around $30 \%$ of all patients in general medical settings exhibit psychiatric disorder, where depression (23\%), anxiety $(22 \%)$, and somatic symptom disorder $(20 \%)$ are the most common disorders. It further stated that delirium can be detected in $10 \%$ of all medical inpatients to as high as $30 \%$ in certain high-risk patient groups. ${ }^{5}$ In the C L study by Grover et al, the seven commonest psychiatric diagnoses were Delirium (23\%), Substance use disorder $(21.1 \%)$, Psychosis (13.6\%), Self harm (13.1\%), Dissociative Disorder (12.8\%), Affective Disorder (8.4\%) and Anxiety Disorder (5.2\%). ${ }^{19}$

In our study the most common psychiatric disorders among the cases referred for evaluation were

substance dependence syndrome (39.2\%), followed by anxiety disorder (17.1\%), delirium due to general medical condition (12.2\%), depression $(6.7 \%)$, seizure disorder $(6.7 \%)$ and intentional self harm (5.5\%).

Suicidal attempt was seen in 3 cases only, which were associated with depression and schizophrenia.

Therefore, the psychiatric diagnoses among the inpatients subjects of our study seem to tally with the common psychiatric diagnoses like in other C L study.

\section{CONCLUSION:}

C L Psychiatry has an important role in diagnosing the psychiatric disorders among the patients with physical illness, leading to the holistic care of the patients. The most common diagnoses to look for are the substance dependence syndrome, anxiety disorder, delirium, depression, seizure disorder, self harm etc.

ACKNOWLEDGEMENT: None

FUNDING: None

\section{CONFLICT OF INTEREST: None}

\section{REFERENCES:}

1. Jan Fawcett, MD, An Update on Consultation Liaison Psychiatry, Psychiatric Annals 47(4):162-162

2. Britta Ostermeyer, MD, MBA, FAPA, Overview of Consultation-Liaison Psychiatry, PSYCHIATRIC ANNALS Vol. 47, No. 4, 2017: 168- 169

3. Ulaş Mehmet Çamsarn and Merve Babahoğlu, Brief History of Consultation-Liaison Psychiatry, its current status and training in Modern Psychiatry : A perspective from the United States, Turkish Journal of Psychiatry 27(4) - December 2016

4. Whiteford HA, Degenhardt L, Rehm J, Baxter AJ, Ferrari AJ, ErskineHE, et al.Global burden of disease attributable to mental and substance use disorders: Findings from the global burden of disease study 2010. Lancet 2013;382:1575- 86.

5. Bronheim HE, Fulop G, Kunkel EJ, et al. The Academy of Psychosomatic Medicine practice guidelines for psychiatric consultation in the general medical setting. The Academy of Psychosomatic Medicine. Psychosomatics. 1998;39:S8-S30.

6. Grover and Avasthi: Consultation-liaison psychiatry services in India. http://www.indianjpsychiatry.org on Sunday, August 18, 2019, IP: 27.34.70.234

7. Gitlin DF, Levenson JL, Lyketsos CG. Psychosomatic medicine: a new psychiatric subspecialty. Acad Psychiatry. 2004;28(1):4-11

8. Ajiboye PO. Consultation-liaison psychiatry: the past and the present. Afr J Med Med Sci. 2007;36:201-5.

9. Lipowski ZJ. Current trends in consultation liaison psychiatry. Can J Psychiatry 1983;28:329 -38 .

10. Zumbrunnen R. Psychiatrie de liaison. La consultation psychiatrique à l'hôpital général. 
Coll Médicine et psychothérapie. Paris: Masson; 1992

11. Smith GC. From consultation-liaison psychiatry to integrated care for multiple and complex needs. Aust N Z J Psychiatry. 2009;43:1-12.

12. Prince $M$, Patel V, Saxena S, Maj M, Maselko J, Phillips $M$, et al. No health without mental health. Lancet. 2007;370:859-77.

13. Ormel J, Vonkorff F, Oldenhinkel AJ, Simon G, Tiemens BG, Ustun TB. Onset of disability in depressed and non-depressed primary care patients. Psychol Med. 1999;29:847-53

14. Saravay SM, Lavin M. Psychiatric comorbidity and length of stay in the general hospital. A critical review of outcome studies. Psychosomatics. 1994;35:233-52

15. Chilshom D, Dichr P, Knap M, Patrick D, Treglia M, Simon G. Depression status, medical comorbidity and re source costs: evidence from an international study of major depression in primary care. Br J Psychiatry. 2003;183:121-31

16. Kishi Y, Meller WH, Kathol RG, Swigart SE. Factors affecting the relationship between the timing of psychiatric consultation and general hospital length of stay. Psychosomatics. 2004;45:470-6

17. Ene $S$. The role of consultation liaison psychiatry in the general hospital. J Med Life 2008;1:429- 31

18. Grover S. State of Consultation Liaison Psychiatry in India: Current status and vision for future. Indian J Psychiatry 2011;53:202- 13.

19. Sandeep Grover, Siddharth Sarkar, Ajit Avasthi, Savita Malhotra, Ashish Bhalla, Subhash K. Varma Consultation-liaison psychiatry services: Difference in the patient profile while following different service models in the medical emergency. http://www.indianjpsychiatry.org on Sunday, August 18, 2019, IP: 27.34.70.234

20. Kelkar DK, Chaturvedi SK, Malhotra S. A study of emergency psychiatric referrals in a teaching general hospital. Indian J Psychiatry 1982;24:366- 9

21 Adityanjee, Mohan D, Wig NN. Determinants of emergency room visits for psychological problems in a general hospital. Int $J$ Soc Psychiatry 1988;34:25- 30

22. Bhatia MS, Agrawal $P$, Khastbir U, Rai S, Bhatia A, Bohra $N$, et al. A study of emergency psychiatric referrals in a government hospital. Indian J Psychiatry 1988;30:363- 8

23. Khan AG, Ansari M, Hayder Z, Hussain M. Pattern of psychiatric emergencies at tertiary care hospital in Karachi. I Pak Psychiatr Soc 2010;7:37-41

24. Silverstone PH. Prevalence of psychiatric disorders in medical inpatients. J Nerv Ment Dis. 1996;184(1):43- 51

25. Hansen MS, Fink P, Frydenberg $M$, Oxhøj $M-L$, Søndergaard L, Munk-Jørgensen P. Mental disorders among internal medical inpatients: prevalence, detection, and treatment status. I Psychosom Res.2001;50(4):199- 204. 